Jap. J. M. Sc. \& Biol., 11, 483-499, 1958

\title{
GROWTH OF VACCINIA VIRUS IN HELA CELLS WITH SPECIAL REFERENCE TO THE PRODUCTION OF SOLUBLE ANTIGENS*
}

\author{
IsAmu TAGAYA and MasahIKo ODA** \\ Department of Virology \& Rickettsiology, National Institute of Health, Tokyo
}

(Received: December 27th, 1958)

As one of the most convenient tools for the study of host-virus relationship, vaccinia virus has widely been used. As for the host earlier works have been concentrated on the rabbit skin, chorioallantoic membrane of embryonated hen's eggs or tissue culture of Maitland type. The first experiment by the use of roller tube tissue culture (Feller et al., 1940) showed that vaccinia virus could grow and continued to exist in high titer in the medium of the plasma clot tissue culture of chick embryo. The discovery of vaccinia hemagglutinin (HA) by Nagler (1942) has thrown a new problem on the growth of vaccinia virus, accompanying the production of hitherto unknown specific soluble substance, although it was found lately that some neuro-vaccinia and rabbit-pox strains and a strain of neurovaccinia passed through Ehrlich ascites tumor cells were devoid of HA production (Fenner, 1958; Cassel, 1957). Recent works on the growth of vaccinia virus on the chorioallantoic membrane of fertile hen's eggs revealed that the initial rise in titer of infective virus was noticed from 8 to 10 hours after infection, being followed by a logarithmic increase thereafter. The first appearance of the measurable HA was observed after the lapse of nearly the same period (Oya, 1955; Metcalf, 1955; Maitland, 1956). Recent advances in tissue culture techniques rendered monolayered cells available in the study of virus. As continuous cell lines, human carcinom HeLa and mouse fibroblast L have widely been used for cytological purposes and virus researches. Scherer and Syverton (1954) and Tyrell (1955) reported that HeLa cells could support the growth of vaccinia virus followed by the development of cytopathic effect. The formation of the inclusion bodies in HeLa cells infected with vaccinia virus was reported by Scherer and Syverton (1954). As compared with HeLa cells L cells do not appear to be suitable for the growth of dermovaccinia virus (Scherer, 1952).

The present work was carried out to get a more detailed aspect of the growth of dermo-vaccinia virus in HeLa cells, with special reference to the mode of production of hemagglutinin and complement fixing antigen, and their release from

* This work was aided in part by a research grant supplied to our Institute from the Rockefeller Foundation, U.S.A.

** Present Address : The Institute for Infectious Diseases, University of Tokyo.

多ケ谷勇・小田昌彥 (国立子防衛生研究所リケッチァウイルス部)

小田昌彥 (現在の所属：東京大学伝染病研究所) 
cells into medium. The mode of growth of the same virus in L cells will be described elsewhere.

\section{Materials ANd Methods}

Virus: Dermo-vaccinia virus, strain Dairen I, was used throughout the work. In our laboratory it was adapted to the chorioallantoic membrane (CAM) of fertile hen's eggs and from 10th to 12th passages were used for the present work (Tagaya, 1954).

Preparation of seed virus: Infected CAM's with confluent lesions were harvested from 66 to 72 hours following inoculation and the virus suspension was prepared by grinding membranes in a mortar with a small amount of alundum and suspending them in $1 \mathrm{cc}$ of phosphatebuffered saline per one membrane. The homogenate was spun at 2,500 rpm for $10 \mathrm{~min}$., and the supernate was lyophilized and stored in a refrigerator to serve as seed virus. The reduction in infectivity by lyophilization was generally about 0.5 in $\log _{10}$ or occasionally negligible and during more than several months seed virus of a constant potency was available throughout a series of experiments. In some experiments in which a heavy inoculum was requested, freshly homogenized CAM's served as seed virus.

Titration of virus: Pock counting titration as described elsewhere (Oya, 1955) was used and pock-forming units (PFU) per bottle were calculated from the volume of the medium or the cell homogenate per one bottle.

Growth medium for HeLa cells: 80\% YLE (Earle's solution supplemented with 0.5\% lactalbumin hydrolysate (N.B.C.), $0.1 \%$ yeast extract (Difco), 500 units per cc of penicillin, 100 gamma per cc of streptomycin and 20 units per cc of mycostatin) and $20 \%$ of filtered bovine serum (BS). Before use penicillin and streptomycin were added to the medium at the concentration of 100 units/cc and 100 gamma/cc respectively and $\mathrm{pH}$ was adjusted to 7.4 with sterile $\mathrm{CO}_{2}$ gas.

Maintenance solution for infected HeLa cells: consisted of $98 \%$ of YLE and $2 \%$ of BS. $\mathrm{pH}$ was adjusted to 7.8 with $7 \%$ solution of $\mathrm{NaHCO}_{3}$.

Phosphate-buffered saline supplemented with $C a$ and $M g(P B S(+))$ : consisted of $0.8 \% \mathrm{NaCl}$, $0.02 \% \mathrm{KCl}, 0.115 \% \mathrm{Na}_{2} \mathrm{HPO}_{4}, 0.02 \% \mathrm{KH}_{2} \mathrm{PO}_{4} 0.01 \% \mathrm{CaCl}_{2}$ and $0.01 \% \mathrm{MgCl}_{2} \cdot 6 \mathrm{H}_{2} \mathrm{O}$.

Phosphate-buffered saline without $\mathrm{Ca}$ and $M g(P B S(-))$ : $\mathrm{PBS}(+)$ devoid of $\mathrm{Ca}$ and $\mathrm{Mg}$.

Hanks.PBS $(+)$ : consisted of equal amounts of Hanks' balanced solution and PBS $(+)$ supplemented with 100 units/cc of penicillin and $100 \mathrm{gamma} / \mathrm{cc}$ of streptomycin. This was used for the washing of cell sheet and for the preparation of seed inoculum.

Diluent for virus and HA titration (PBS) : $0.85 \%$ saline solution buffered at $\mathrm{pH} 7,4$ with M/150 Sörensen's phosphate buffer solution. For virus t:tration, it was spplemented with 100 units/cc of penicillin and 100 gamma/cc of streptomycin.

HeLa cells: originally sent to our Institute from Dr. Syverton. The routine passage was carried out with medium above-described. For the experimental subculture versenated cells centrifuged at $1,000 \mathrm{rpm}$ for $3 \mathrm{~min}$., the sedimented cells were resuspended in the growth medium and $3.0 \mathrm{cc}$ each was dispensed into bottles of $3.5 \times 3.5 \times 5.5 \mathrm{~cm}$. Before use they were incubated at $37^{\circ} \mathrm{C}$ for 4 days. At the time of infection cells per one bottle were from 2 to $5 \times 10^{6}$ as estimated by the nuclei counting method using hypotonic citric acid (Sanford et al., 1951 ; Takano et al., 1956).

Inoculation of virus: Before inoculation the medium of the culture was withdrawn, and the cell sheet was washed with three changes of $3.0 \mathrm{cc}$ each of Hanks.PBS $(+)$. Three cc aliquot of the seed virus diluted with Hanks $\cdot \operatorname{PBS}(+)$ was added to one bottle and the bottles were incubated at $37^{\circ} \mathrm{C}$ for one hour for the adsorption of the virus. Subsequently the inoculum was aspirated off and pooled into a bottle. Four washings of the cell sheet followed, employing $3.0 \mathrm{cc}$ each of Hanks-PBS(+) per one bottle and the fluid was pooled into the withdrawn inoculum to serve for the titration of unadsorbed virus. The washing procedure 
was repeated once more and the pooled fluid was titrated separately. Three cc each of the maintenance solution was added to the bottles, which were returned into an incubator at $37^{\circ} \mathrm{C}$. Two or three bottles were set as control, which were given the same amount of Hanks.PBS $(+)$ instead of viral inoculum and underwent the same treatment as those infected did.

Harvest of the infected culture: Before the addition of the maintenance solution three infected bottles were set aside to titrate the amount of the residual virus, which remained associated with cells even after the washing procedures above-described. Three cc of $0.02 \%$ versene solution in $\operatorname{PBS}(-)$ was added to each bottle and they were kept in an incubator at $37^{\circ} \mathrm{C}$ for $10 \mathrm{~min}$., after which the pooled cell suspension was centrifuged at $1,000 \mathrm{rpm}$ for $3 \mathrm{~min}$. The sedimented cells were washed in the same amount of $\operatorname{PBS}(-)$, recentrifuged and finally the cells were suspended in $3.0 \mathrm{cc}$ of PBS $(1 \mathrm{cc} / \mathrm{bottle})$, which were ground in a glass homogenizer of Potter-Elvejem type. The homogenizing procedures were carried out twice, 2 min. each, cooling the tube from outside with finely granulated ice. By preliminary tests the procedures were considered satisfactory for the complete destruction of the cells. The homogenate was spun at 2,500 rpm for $10 \mathrm{~min}$. and the supernate served for biological tests. At specified time intervals aliquots of 3 bottles were taken out of the incubator, the medium was withdrawn to be pooled and the cells were treated in the same manner as described above. The pooled medium was centrifuged at 1,000 rpm for $3 \mathrm{~min}$. and the supernate served for biological examinations. In order to minimize the loss of cell-associated virus, especially when cell-sloughing was remarkable, the same centrifuge tube was used for the sedimentation of the versenated cells together with the sedimented cells from the medium. Titration of infective virus and HA was carried out immediately after the harvest of the materials, which were kept in a refrigerator from 0 to $2^{\circ} \mathrm{C}$ before the complement fixation test was carried out.

HA titration: As described elsewhere (Tagaya, 1954; Oya, 1955), two sets of doubling dilutions $(0.25 \mathrm{cc})$ of antigen were made. To one set were added $0.1 \mathrm{cc}$ of $1: 30$ diluted normal rabbit serum and $0.15 \mathrm{cc}$ of $0.5 \%$ suspension of susceptible fowl red blood cells and the other received $0.1 \mathrm{cc}$ of $1: 30$ diluted immune rabbit serum instead of normal rabbit serum. Reading was made after 60 min. standing of the rack in an incubator at $37^{\circ} \mathrm{C}$ and titers were expressed as the reciprocals of the final dilution of antigen in the normal rabbit serum set, which showed clearly visible partial agglutination. The specificity of the reaction was simultaneously checked by the immune serum set.

Complement fixation test: carried out after the method described by Craigie and Wishart (1986a) with a slight modification. As diluent $0.85 \%$ saline solution supplemented with $0.001 \mathrm{M}$ $\mathrm{MgCl}_{2}$ was employed. Three units of hemolysin and two full units of complement were used and the mixture of antigen, antiserum and complement was left standing in a refrigerating chamber from 2 to $5^{\circ} \mathrm{C}$ for 18 hours before the hemolytic system was added. A serial two fold dilution of antigen was tested against an appropriate dilution of rabbit hyperimmune serum and the titers were expressed arbitrarily as the reciprocals of the highest dilution of antigen which showed $75 \%$ hemolysis inhibition. To check the specificity of the reaction another set of tubes was prepared, which received normal rabbit serum at the same concentration instead of immune rabbit serum.

Rabbit immune sera: obtained from rabbits immunized with rabbit dermal pulp. For the complement fixation test the same hyperimmune serum (No. 551) prepared after the method of Craigie and Wishart (1936a) was employed throughout the present work at the dilution of $1: 16$, which showed positive complement fixation with $1: 3,200$ diluted infected CAM antigen. Just before use the serum was inactivated at $56^{\circ} \mathrm{C}$ for $30 \mathrm{~min}$. or at $60^{\circ} \mathrm{C}$ for $10 \mathrm{~min}$. For the HA titration were used sera obtained from the rabbits infected 3 weeks previously on the scarified skin of the back and flanks. The serum was inactivated at $56^{\circ} \mathrm{C}$ for $30 \mathrm{~min}$. before use. 
Microscopic observation: Before harvest bottles were examined microscopically to check the degenerative change of the cells. Staining of the harvested cells was not usually carried out.

\section{EXPERIMENTAL}

\section{Efficiency of Adsorption of Virus onto HeLa Cells and the Effect of Repeated Washings on the Removal of the Residual Virus}

In order to get informations on the initial rise in titer of infective particles or soluble antigens it is desirable to synchronize the initiation of infection, for which the removal of unadsorbed virus from cell surface after a certain time interval of virus-cell contact is one of the most important problems. Information on the efficiency of adsorption of inoculated virus onto host cells will be requested as well for the detailed analysis of host-virus interaction. Preliminary experiments along this line led the authors to the conclusion that with our experimental methods it is impossible to annul the residual infective virus which remained associated with cell surface and that it is unreasonable to deduce the amount of adsorbed virus from that recovered in the residue of the inoculum and in the washings, which in some cases exceeded the amount of the input, probably due to the dissociation of the clumps of virus during the adsorption period. Maitland (1956) noticed the same phenomenon in his experiments with CAM. As a rule, by five washings carried out after the removal of the inoculum the amount of recoverable virus in the cell homogenate was reduced to about $1 / 1,000$ as compared with that contained in the original inoculum. $\mathrm{HA}$ and $\mathrm{CF}$-(complement fixing)antigen were always below the detectable level in the cell homogenate thus otained.

\section{Influence of Bovine Serum on the Growth of Vaccinia Virus in HeLa Cells}

Preliminary tests showed that normal bovine sera obtained from a slaughterhouse had a slight inactivating effect on vaccinia virus at $37^{\circ} \mathrm{C}$, when mixed with YLE at the concentration of $2 \%$ as employed routinely in our laboratory to maintain the infected cells. Different lots of bovine sera, including calf sera, showed, more or less, the same effect, i.e. drop in virus titer by 0.7 to 1.0 in $\log _{10}$, when about $10^{4} \mathrm{PFU} / \mathrm{cc}$ of virus were mixed in the maintenance solution and kept as a thin layer in a rubber-stoppered tissue culture bottle. The inactivating effect was noticed as early as 3 hours after the incubation of the mixture, but no further decrease in virus titer was observed during the subsequent 48 hours. This led us to examine if any difference might exist in the yield of virus between the cells kept under the maintenance solution containing bovine serum and those kept under YLE only.

$6.8 \times 10^{6}$ of $\mathrm{HeLa}$ cells were infected with $10^{4.8} \mathrm{PFU}$ of virus, and after one hour's adsorption followed by the subsequent washing procedures, they were maintained under YLE with or without bovine serum. Three bottles of each group were harvested daily and the infective virus, $\mathrm{HA}$ and $\mathrm{CF}$-antigen in the medium and cell homogenate were titrated. As shown in Fig. 1, no difference in the growth curve was observed between them. This indicates that the inactivating effect of 
bovine serum is not so strong as to have any influence upon the growth of vaccinia virus in HeLa cells. A slight difference, however, was seen in the development of cytopathic effect, i.e. the cells maintained with serum showed more remarkable degeneration after 3 days' incubation than did those kept without serum, and the sloughing of cells from glass wall began earlier and was heavier in the former than in the latter. On the contrary control cells kept under YLE only became granulated a little earlier than those given bovine serum. Consequently the maintenance solution containing bovine serum at $2 \%$ was used throughout further experiments.
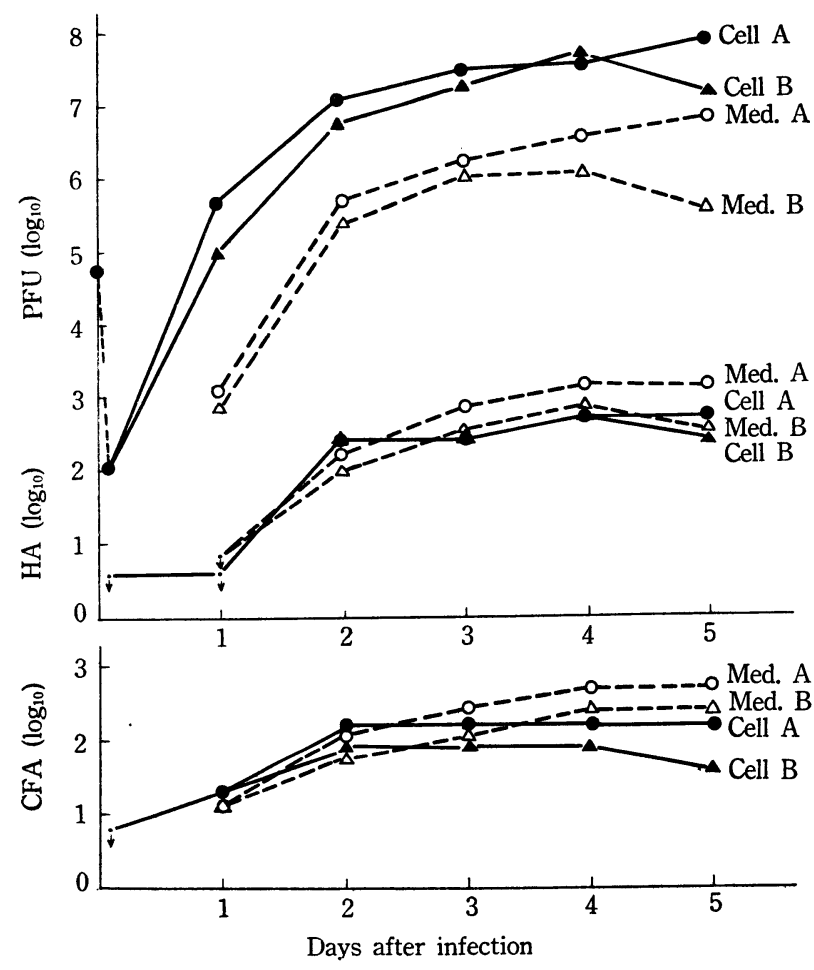

Fig. 1. Growth of vaccinia virus in HeLa cells maintained with or without bovine serum.

Average cell number: $6.8 \times 10^{6} /$ bottle.

A..........with bovine serum $(2 \%)$.

B.........without bovine serum.

\section{Growth of Vaccinia Virus in HeLa Cells Infected with} Varying Amounts of Vaccinia Virus

As shown in Fig. 1 (curve A), the growth of vaccinia virus in HeLa cells infected with a relatively small amount of virus was remarkable during the first two days and the maximal titer was obtained 3 or 4 days after infection. The virus in the medium increased in parallel with that in the cells, showing a difference in 
titer by one $\log _{10}$ between them. Measurable HA first appeared 48 hours after inoculation in the medium and in the cells, and the medium titer rose gradually thereafter to surpass the cell titer. The $\mathrm{CF}$-antigen was detectable in the medium and in the cells one day earlier than $\mathrm{HA}$ and the pattern of the curves was nearly the same as those of HA.

In the next experiment the initial stage of virus reproduction was followed at shorter time intervals. Fig. 2 presents the results with an inoculum 10 times larger

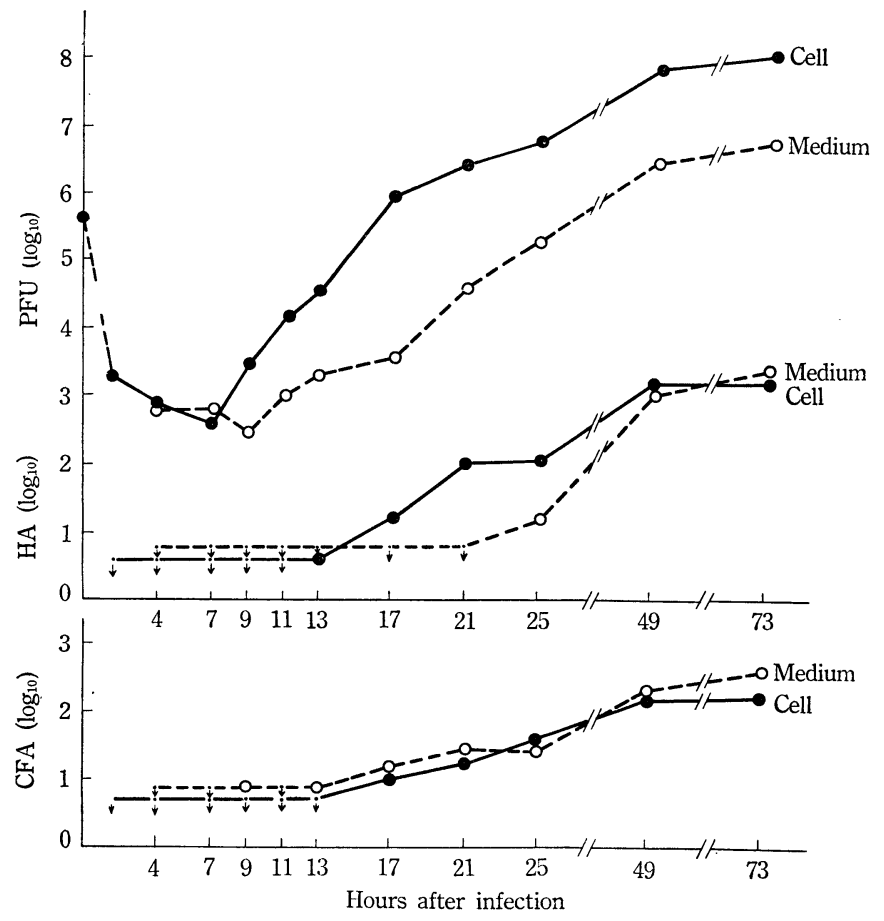

Fig. 2. Growth of vaccinia virus in HeLa cells. Average cell number: $2.4 \times 10^{6} /$ bottle.

than that of the experiment in Fig. 1. The first significant rise in cell virus was 11 hours following infection, followed by a continual and gradual increase during the subsequent 12 hours and the maximal titer was obtained in the 49 hours' harvest. The release of infective particles into the medium was delayed by several hours and then its titer rose in parallel with that of cell virus, keeping a nearly constant difference of from 1 to 1.5 in $\log _{10}$ lower as compared with the latter.

The general trend of the growth curve of vaccinia virus in HeLa cells given a larger inoculum or a smaller one was the same as the preceding, showing the initial rise in cell virus from 10 to 12 hours following infection and that in medium virus several hours later. One of the typical experiments is depicted in Fig. 3, in which $10^{6.5}$ cells were infected with $10^{8} \mathrm{PFU}$ of virus. 
In these experiments HA was detected first in the cells 10 hours (Fig. 3) or 13 hours (Fig. 2) after inoculation and increased gradually as the virus titer rose. The measurable amount of HA was not accumulated in the medium before 16 hours (Fig. 3) or 25 hours (Fig. 2) following infection, after which a similar curve, but with a steeper slope, was obtained as compared with that of cell HA. Consequently in later stages medium HA was higher than cell HA, while medium virus was about $1 / 10$ of cell virus (Figs. 1 and 2 ). This suggests the difference of the ease with which virus particles or HA come out of the cells.

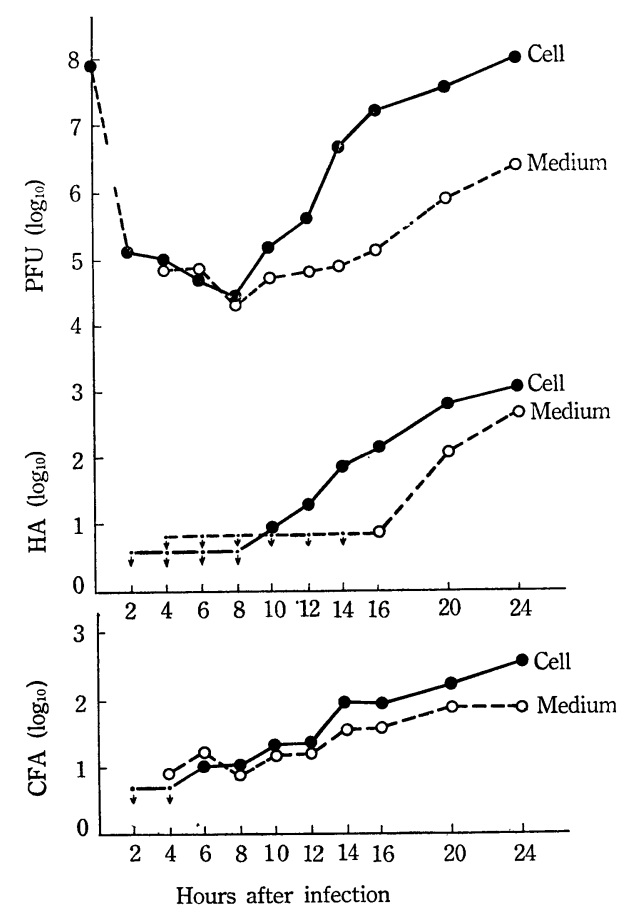

Fig. 3. Growth of vaccinia virus in HeLa cells infected with a large inoculum.

Average cell number : $3.2 \times 10^{6}$.

The first appearance of detectable CF-antigen in the cells was 6 hours following infection when the cells were infected with a heavy inoculum and 17 hours after infection, when they were given a less inoculum. In the medium, however, a small amount of $\mathrm{CF}$-antigen was detectable earlier, i.e. 4 and 7 hours following inoculation respectively. The cell CF-antigen increased gradually after its appearance, but the medium $\mathrm{CF}$-antigen remained around the detectable level during several hours following its first appearance. It is to be elucidated if the CF-antigen measurable earlier in the medium than in the cells is newly produced or originated from inoculum modified by host cells. Generally the amount of the medium CFantigen later surpassed that of the cell $\mathrm{CF}$-antigen. 


\section{The Release of Vaccinia Virus from the Cells into the Medium}

The preceding experiments showed that the virus titer in the cells was always higher than the medium virus titer over the period observed and no evidence of the burst release of mature virus as observed in T-bacteriophages has ever been given. An experiment was, therefore, set forth to see the change of virus titer

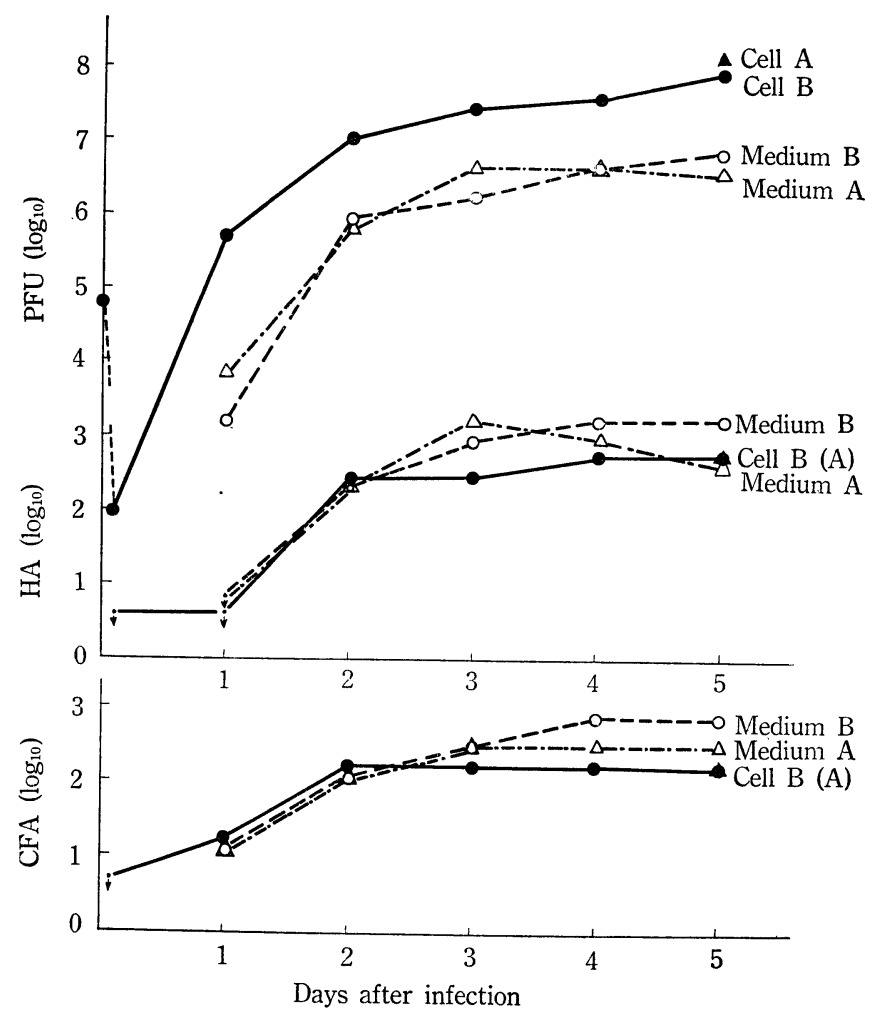

Flg. 4. Growth of vaccinia virus in HeLa cells with or without daily replacement of the medium.

Average cell number: $6.8 \times 10^{6} /$ bottle.

A........The medium was replaced daiy with fresh one.

B.........Without medium replacement.

in the medium, which was replenished daily with fresh maintenance solution. As a control, aliqout of 3 bottles was harvested every day, which were infected in the same manner and of which the medium was left unchanged. After 5 days, when the experiment was terminated, the cells of the medium-change group were harvested. As illustrated in Fig. 4, the amount of infective virus, HA or CF-antigen in the medium was approximately at the same level in either group. It may be worthy of notice that nearly the same amount of virus or soluble antigens was found in the medium renewed 24 hours before as in the medium of the control 
bottles. In another experiment, which was designed to investigate the problem in more detail, 19 bottles $(5 \times 5 \times 10 \mathrm{~cm})$ of HeLa cell culture were prepared, of which 16 were inoculated with $10^{6.2} \mathrm{PFU}$ of vaccinia virus per one bottle and one served as control. Average cell number per one bottle as estimated by the nuclei counting of the other 2 bottles was $1.2 \times 10^{7}$. After one hour's adsorption of virus, followed by the subsequent washing of the cell sheet, the bottles were given $10 \mathrm{cc}$ of the maintenance solution and incubated in an incubator at $37^{\circ} \mathrm{C}$. At specified time intervals aliquots of 2 bottles were harvested, of which the cell homogenates and the medium were tested biologically. Otherwise, 0.3 or $0.4 \mathrm{cc}$ (according to the quantity needed) of the medium was withdrawn out of each bottle to be pooled for titration, and the incubation was continued. The medium of the half of the remaining bottles was replaced with fresh maintenance solution after 24 hours following infection. Periodical withdrawal of 0.3 or $0.4 \mathrm{cc}$ aliquot of the medium from each bottle of the medium-change group was carried out at intervals during the subsequent 24 hours, after which 2 bottles randomly selected from each group, i.e. the medium-change group and the non-medium-change group, were harvested. The results are tabulated in Table 1 , which indicates that infective particles were released so rapidly into the fresh medium that, after 5 hours following the medium change, it contained the same amount of virus as it did before the replacement. The situation was the same as regards $\mathrm{HA}$, but the $\mathrm{CF}$-antigen seemed to be released more slowly.

Table 1. Release of infective particles and soluble antigens into the fresh medium

\begin{tabular}{|c|c|c|c|c|c|c|}
\hline \multirow{2}{*}{$\begin{array}{l}\text { Hours after } \\
\text { infection }\end{array}$} & \multicolumn{3}{|c|}{ Medium } & \multicolumn{3}{|c|}{ Cell } \\
\hline & PFU* & $\mathrm{HA}^{*}$ & $\mathrm{CFA}^{*}$ & PFU* & $\mathrm{HA}^{*}$ & $\mathrm{CFA}^{*}$ \\
\hline 3 & 3.0 & - & $<1.4$ & 2.8 & - & 1.0 \\
\hline 7 & 3.5 & - & $<1.4$ & & & \\
\hline 12 & 3.5 & - & $<1.4$ & & & \\
\hline 16 & 4.0 & $<1.3$ & 1.7 & & & \\
\hline 20 & 4.4 & 1.3 & 1.7 & & & \\
\hline 24 & 5.2 & 1.3 & 2.3 & 6.7 & 2.4 & 2.3 \\
\hline
\end{tabular}

The medium was replaced here.

\begin{tabular}{lcrrrrrr}
$24-40^{\prime}$ & $\left(30^{\prime}\right)^{* *}$ & 4.5 & $<1.3$ & 1.4 & & & \\
29 & $(5)$ & 5.4 & 1.3 & 2.0 & & & \\
33 & $(9)$ & 5.6 & 1.6 & 2.0 & & & \\
38 & $(14)$ & 5.7 & 2.2 & 2.3 & & & \\
48 & $(24)$ & 6.1 & 2.5 & 2.6 & 7.3 & 3.3 & 2.8 \\
& & $* * * 5.9$ & 2.5 & 2.6 & 7.3 & 3.3 & 2.8 \\
\hline
\end{tabular}

Average cell number: $1.2 \times 10^{7} /$ bottle. Inoculum : $10^{6.2} \mathrm{PFU} /$ bottle.

* Titers are expressed in $\log _{10}$. - : not done.

** Numeral in parenthesis is the time after the reincubation of the bottles following the medium replacement.

*** Samples collected from the bottles, of which the medium was left untouched. 


\section{The Ratio of Infective Particles to HA- or CF-Antigen in the Cells or in the Total Culture}

It has been shown that the ratio PFU/HA is generally constant in CAM infected with vaccinia virus (Oya, 1955; Metcalf, 1955; Maitland, 1956). These data,

Table 2. Ratio PFU/HA in HeLa cell culture infected with vaccinia virus

\begin{tabular}{|c|c|c|c|c|c|c|c|c|}
\hline \multirow{2}{*}{$\begin{array}{l}\text { Exp. } \\
\text { No. }\end{array}$} & \multirow{2}{*}{ Inoculum } & \multirow{2}{*}{$\begin{array}{l}\text { Time after } \\
\text { inoculation** }\end{array}$} & \multicolumn{3}{|c|}{ Cell } & \multicolumn{3}{|c|}{ Cell+Medium } \\
\hline & & & PFU* & $\mathrm{HA}^{*}$ & RATIO* & PFU* & $\mathrm{HA}^{*}$ & RATIO* \\
\hline \multirow[t]{5}{*}{26} & 5.7 & (11) & 4.6 & 0.6 & 4.0 & & & \\
\hline & & (13) & 5.0 & 0.9 & 4.1 & & & \\
\hline & & (17) & 5.8 & 1.5 & 4.3 & & & \\
\hline & & (21) & 5.6 & 1.8 & 3.8 & & & \\
\hline & & $(25)$ & 7.2 & 2.7 & 4.5 & 7.2 & 2.7 & 4.5 \\
\hline \multirow[t]{6}{*}{33} & 5.6 & (13) & 4.5 & 0.6 & 3.9 & & & \\
\hline & & (17) & 5.9 & 1.2 & 4.7 & & & \\
\hline & & (21) & 6.4 & 2.1 & 4.3 & & & \\
\hline & & $(25)$ & 6.8 & 2.1 & 4.7 & 6.8 & 1.5 & 4.3 \\
\hline & & 2 & 7.9 & 3.0 & 4.9 & 7.9 & 3.3 & 4.6 \\
\hline & & 3 & 8.0 & 3.0 & 5.0 & 8.1 & 3.4 & 4.7 \\
\hline 34 & 7.7 & 1 & 7.8 & 2.7 & 5.1 & 7.8 & 4.9 & 4.9 \\
\hline \multirow[t]{4}{*}{43} & 4.8 & 2 & 7.0 & 2.4 & 4.6 & 7.1 & 2.7 & 4.4 \\
\hline & & 3 & 7.4 & 2.4 & 5.0 & 7.4 & 3.0 & 4.4 \\
\hline & & 4 & 7.5 & 2.7 & 4.8 & 7.6 & 3.3 & 4.3 \\
\hline & & 5 & 7.8 & 2.7 & 5.1 & 7.8 & 3.3 & 4.5 \\
\hline \multirow[t]{4}{*}{$43^{\prime}$} & 4.8 & 2 & 6.7 & 2.4 & 4.3 & 6.7 & 2.6 & 4.1 \\
\hline & & 3 & 7.3 & 2.4 & 4.9 & 7.3 & 2.8 & 4.5 \\
\hline & & 4 & 7.7 & 2.7 & 5.0 & 7.7 & 3.1 & 4.6 \\
\hline & & 5 & 7.1 & 2.4 & 4.7 & 7.1 & 2.8 & 4.3 \\
\hline \multirow[t]{3}{*}{47} & 6.3 & 1 & 6.4 & 2.1 & 4.3 & 6.4 & 2.1 & 4.3 \\
\hline & & 2 & 7.5 & 2.7 & 4.8 & 7.5 & 3.1 & 4.2 \\
\hline & & 3 & 6.9 & 2.4 & 4.5 & 6.9 & 3.3 & 3.6 \\
\hline \multirow[t]{6}{*}{62} & 7.9 & (10) & 5.2 & 0.9 & 4.3 & & & \\
\hline & & (12) & 5.9 & 1.2 & 4.7 & & & \\
\hline & & (14) & 6.7 & 1.8 & 4.9 & & & \\
\hline & & (16) & 7.2 & 2.1 & 5.1 & 7.2 & 2.1 & 5.1 \\
\hline & & (20) & 7.5 & 2.7 & 4.8 & 7.5 & 2.8 & 4.7 \\
\hline & & (24) & 7.9 & 3.0 & 4.9 & 7.9 & 3.1 & 4.8 \\
\hline
\end{tabular}

* Titers are expressed in $\log _{10}$.

** Numeral in parenthesis is the time in hour, otherwise time in day. Average PFU/HA in the cells befere the accumulation of measurable HA in the medium: $4.30 \pm 0.23$

Average ratio $\mathrm{PFU} / \mathrm{HA}$ in the total culture (cell + medium) $: 4.46 \pm 0.14$ 
however, were obtained in the infected tissue exposed to air, though closed by egg shell and no differentiation was made between the intracellular and extracellular components. Maitland collected a small amount of the liquid accumulated on the surface of the dropped area of CAM, but the quantity of the liquid fluctuates so widely from egg to egg that it is likely to be extremely difficult to keep the infected tissue under constant conditions in relation to the liquid.

Taking advantage of tissue culture system, which allows a continuous cell line to be maintained under relatively uniform conditions, comparison was made of the ratio of infective particles to HA titer in the cell homogenate and in the medium. In Table 2 are presented 29 results from 7 experiments. It was noticed that the ratio in the cells at an earlier stage of infection, when no measurable amount of HA was yet accumulated in the medium, was lower than those at later stages. However, in consideration of the difference in the pattern of the curves between infective particles and $\mathrm{HA}$, it will be more reasonable to compare the ratio of the total culture (cell homogenate titer plus medium titer), as the consideration of thermal degradation is not likely to be important under the experimental conditions. As shown in Table 2 and Fig. 5, the ratio PFU/HA of the total culture was nearly

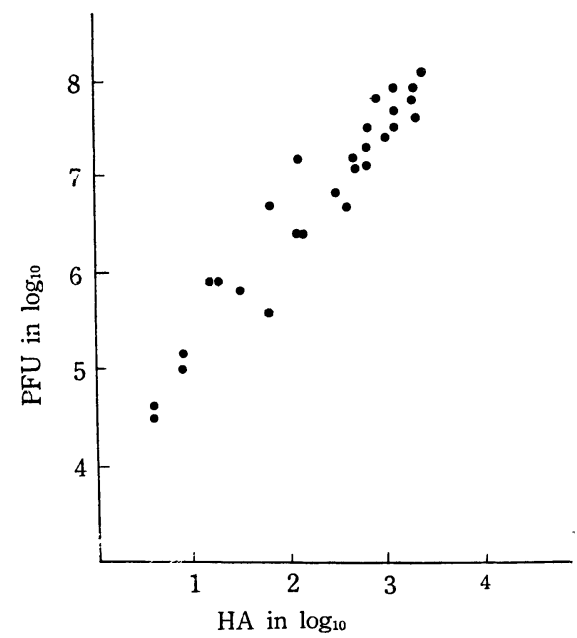

Fig. 6. Infective titer of HeLa cell culture in relation to the amount of $\mathrm{HA}$.

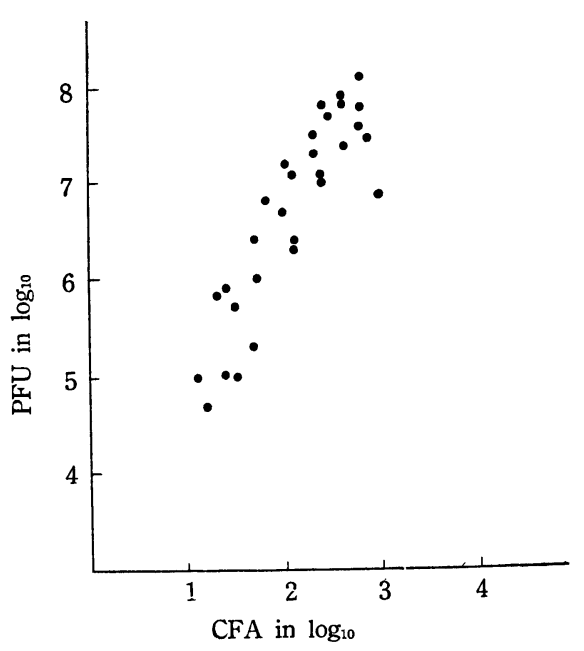

Fig. 6. Infective titer of HeLa cell culture in relation to the amount of CFA.

constant, even at later stage, when a large amount of HA was measurable in the medium. The average ratio at early stage was $4.30 \pm 0.23$ in $\log _{10}$, while that after the appearance of measurable $\mathrm{HA}$ in the medium was $4.46 \pm 0.14$. The difference is not statistically significant.

The ratio PFU/CFA (CF-antigen) was examined as well and proved to be nearly constant after the appearance of the antigen in the cells, if the ratio in total culture was compared (Fig. 6). The earlier appearance of a small amount of CF-antigen in the medium, however, is one of the problems to be elucidated. It is already established that vaccinia virus contains a certain amount of CF-antigen as surface antigen, which is freed gradually when washed elementary bodies are kept standing 
as suspension in saline (Craigie and Wishart, 1936b) and the nucleo-protein bound CF-antigen within elementary bodies was reported by Smadel et al. (1942). A portion of the medium $\mathrm{CF}$-antigen might be accounted for by the antigen freed from infective particles either newly produced or of inoculum origin, which did not participate in infection. This makes it difficult to evaluate the accurate amount of CF-antigen produced in the infected cells.

\section{Influence of the Incubation Temperature Following Infection on the Growth of Vaccinia Virus and the Production of Soluble Antigens in HeLa Cells}

An attempt was made to test the possibility of modifying the mode of the reproduction of infective particles and soluble antigen, e.g. the ratio $\mathrm{PFU} / \mathrm{HA}$, by incubating the infected culture under lower temperatures. As illustrated in Fig. 7,

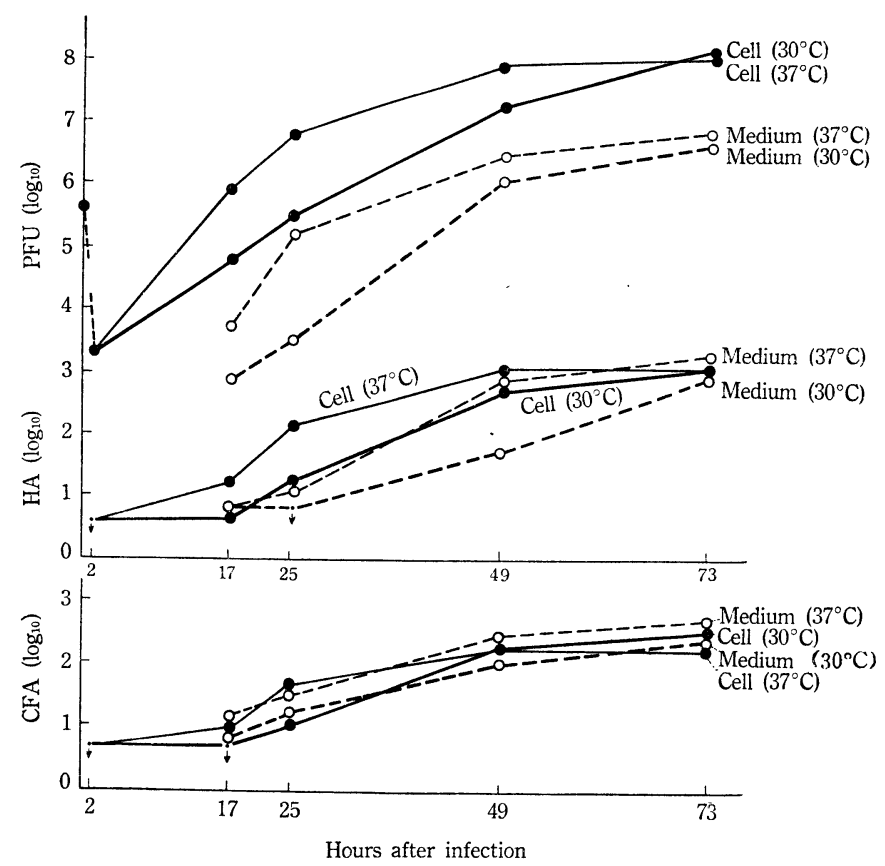

Fig. 7. Growth of vaccinia virus in $\mathrm{HeLa}$ cells kept at $30^{\circ} \mathrm{C}$. Average cell number: $2.4 \times 10^{6}$.

delay in the growth of infective particles and in the production of soluble antigens was observed, when the infected culture was kept at $30^{\circ} \mathrm{C}$ after the routine washing procedure following one hour's adsorption of virus at $37^{\circ} \mathrm{C}$, but the ratio $\mathrm{PFU} / \mathrm{HA}$ was within the range obtained in the experiments carried out at $37^{\circ} \mathrm{C}$. Another experiment with the post-incubation temperature at $30^{\circ} \mathrm{C}$ and $20^{\circ} \mathrm{C}$ indicated that no significant growth of virus occurred at $20^{\circ} \mathrm{C}$ during the course of 3 days, while the same growth pattern of virus was observed at $30^{\circ} \mathrm{C}$ as shown in the preceding experiment. Neither the cell homogenate nor the medium of the infected culture 


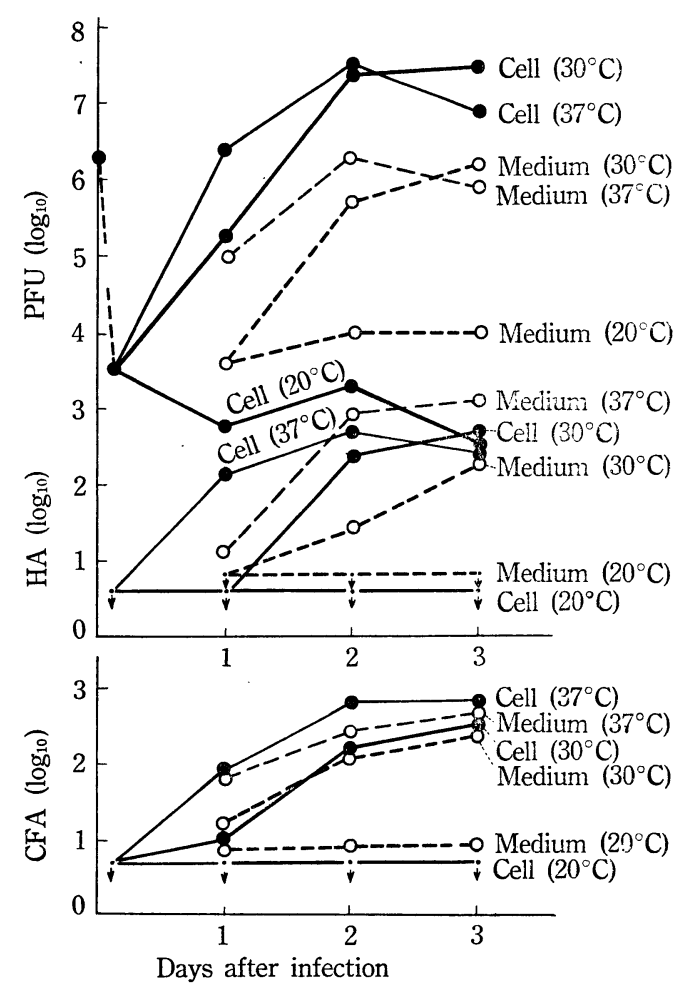

Fig. 8. Growth of vaccinia virus in $\mathrm{HeLa}$ cells kept at $30^{\circ} \mathrm{C}$ and $20^{\circ} \mathrm{C}$. Average cell number: $5.0 \times 10^{6} /$ bottle.

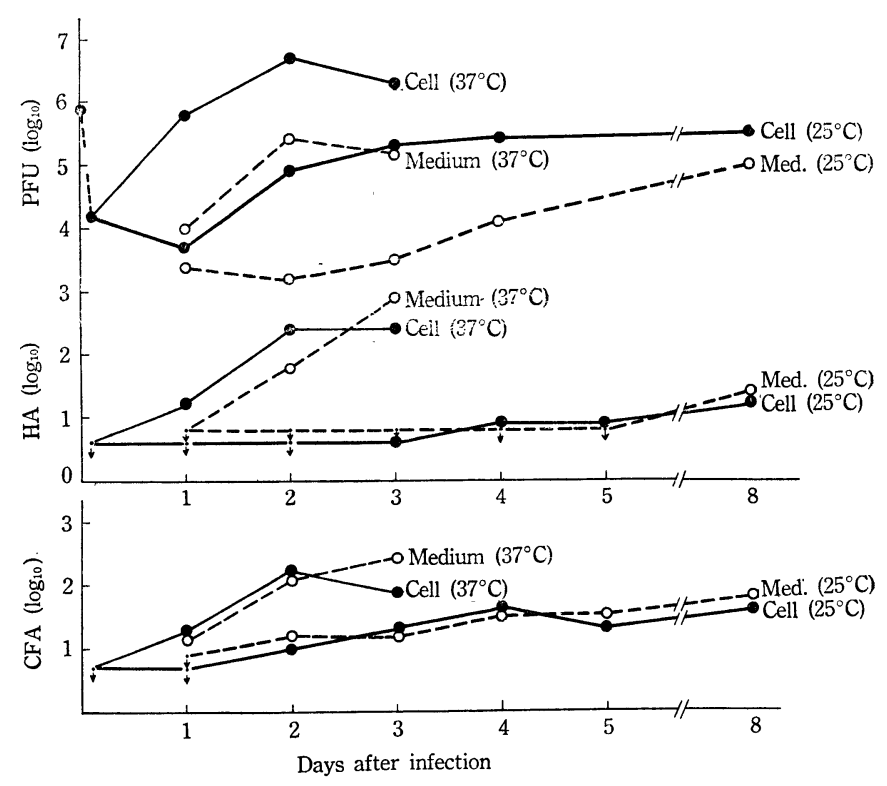

Fig. 9. Growth of vaccinia virus in HeLa cells kept at $25^{\circ} \mathrm{C}$.

Average cell number: $4.9 \times 10^{7}$.

Virus titer on the 5 th day was discarded on account of obscured eruptions. 
kept at $20^{\circ} \mathrm{C}$ contained any trace of soluble antigens over the detectable level, with the sole exception that the minimal amount of $\mathrm{CF}$-antigen was found in the medium over the whole period of the experiment (Fig. 8). This appears to suggest that such a small amount of $\mathrm{CF}$-antigen found in the medium in early stage might be accounted for as originated from the inoculum. Informations given by the experiment depicted in Fig. 9 indicated that $25^{\circ} \mathrm{C}$ was the critical temperature for the growth of vaccinia virus in HeLa cells, though the growth was very slow and the yield was considerably low. However, no significant change in the ratio PFU/HA was observed.

\section{Discussion}

Detailed investigations on the mode of growth of vaccinia virus in HeLa cells revealed that the sequences taking place in these cells were quite similar to those observed in the chorioallantoic membrane of embryonated hen's eggs (Oya, 1955; Metcalf, 1955; Maitland, 1956). The first rise in titer of the infective particles was observed in the cells about 10 hours following infection, followed by a logarithmic increase, which was established by Oya (1955) and Metcalf (1956) with the chorioallantoic membrane of embryonated hen's eggs. In coincidence with this initial rise in virus titer within the cells, hemagglutinin became measurable in the cell homogenate, which continued to increase during the period of viral growth. The detection of the hemagglutinin in the medium delayed by several hours. The curve of the medium virus showed the same pattern, where a significant rise in titer was noticed several hours after the initial rise of the cell virus. The amount of the medium virus was about $1 / 10$ of that of the cell virus over the period of observation, although a larger portion of the cells became degenerated in later stages. The amount of the medium hemagglutinin, however, transcended that of the cell hemagglutinin in later stages. Consequently it is suggested that the hemagglutinin may be released more easily from the cells than the infective particles. As determined preliminarily, thermal degradation of the infective particles in the medium used does not appear to play an important role for the evaluation of the growth curve, and there is no way of approach to see the degradation of the infective particles or the soluble antigens in the medium where infected cells coexist. The ratio PFU/HA was nearly constant in the cells harvested in the initial stage of infection, when no measurable amount of hemagglutinin was yet accumulated in the medium. As the hemagglutinin became released from the cells, the ratio in the cells showed a trend to be elevated slightly, while the ratio total $\mathrm{PFU} /$ total HA in the culture was not modified significantly. The average ratio $\mathrm{PFU} / \mathrm{HA}$ was $4.41 \pm 0.12$ in $\log _{10}$, which was a little lower than that reported by Oya $(1955,1956)$, who used as host the chorioallantoic membrane of 11-12 day eggs and the one-day-old fertile hen's eggs, employing the same technique for the biological titrations. The difference of host cells and that of the environments, under which infected cells were placed may be accounted for as a probable cause of the difference in the ratio. Recently Fenner (1958) showed that some strains of neurovaccinia and rabbit-pox viruses do not produce hemagglutinin in the chorioallantoic membrane of fertile hen's eggs and Cassel (1957) reported on the elimination of the hemagglutinin production of a strain of neuro-vaccinia virus by serial passages of the virus through Ehrlich's mouse ascites tumor cells. These data appear to 
indicate that the hemagglutinin is not the essential substance in the course of poxvirus reproduction. The constant ratio, however, with which infective particles and hemagglutinin are synthesized in the cells infected with dermo-vaccinia virus suggests that this soluble substance should not be neglected for the full understanding of the synthesis of vaccinia virus. The failure in an attempt to modify the ratio by changing the post-incubation temperature appears to suggest a close relationship between the sequences of the synthesis of these two substances.

When HeLa cells were infected with a large inoculum, complement fixing antigen in the cells reached the detectable level a little earlier than the hemagglutinin did or the infective particles showed a significant rise in titer. This does not necessarily mean that the complement fixing antigen is first synthesized in the infected cell, though no evidence to exclude the possibility has ever been exemplified. The difference in sensitivity of detecting antigens makes the comparison more complicated and no informations have ever been obtained concerning the fate of surface or nucleoprotein-bound complement fixing antigen of the elementary bodies after they entered into the cells. A small amount of the complement fixing antigen was measurable in the medium before the antigen could be detected in the cells and it was suggested that this antigen might not be that newly produced in the infected cells but be derived from the inoculated virus itself (probably the residual virus), because it was also found in the medium of the infected culture kept at $20^{\circ} \mathrm{C}$, where no significant viral growth occurred. Another fact which is likely to support the view is that the medium complement fixing antigen remained around the detectable level for several hours and did not show any significant rise in titer before the detectable amount of the antigen was accumulated within the cells. Maitland (1956) suggested a direct relationship between the numbers of elementary bodies and the amount of complement fixing antigen produced in the chorioallantoic membrane of fertile hen's eggs and our data appear to be favorable for the view. (Fig. 6). However, to get more detailed informations on the reproduction of the complement fixing antigen of vaccinia virus, it will be requested to differentiate the reproduction of LS-antigen (Craigie and Wishart, 1936b) and that of NP-antigen. NP-antigen was reported by Smadel et al. (1942) as being bound to the nucleoprotein of the elementary bodies. In the present work no consideration was made about this problem, chiefly due to technical difficulties. Consequently it appears to be too early at this moment to discuss on the amount of the complement fixing antigen produced in the cells.

It is interesting that the cell virus titer was always higher than the medium virus titer, even after the degeneration of cells became remarkable and a larger portion of the cells sloughed from the glass wall. It is thus suggested that vaccinia virus is not likely to be released easily out of the cell. A certain amount of virus, however, was freed from the cells in a shorter period of time, when the medium was renewed during the period of active virus growth in the cells. When examined after 5 hours following medium replacement, the medium virus was shown to have recovered its titer. It must be taken into consideration that the imbalance between the fresh medium and the cells might partly account for the rapid recovery of the equilibrium of the virus titer between them.

When HeLa cells infected with vaccinia virus were incubated further at lower temperature, growth of virus and the production of soluble antigens were retarded, 
and especially at $25^{\circ} \mathrm{C}$, which is considered to be the critical temperature for the growth of vaccinia virus in this host cell, maximal titer was irregular, in some cases lower and in others the same as compared with those obtained at $37^{\circ} \mathrm{C}$, while the culture kept at $30^{\circ} \mathrm{C}$ gave rise to the same maximal titer as that kept at $37^{\circ} \mathrm{C}$. At $20^{\circ} \mathrm{C}$ no evidence was obtained as to the growth of infective particles.

As revealed in the present work HeLa cells are considered to be one of the most convenient host cells for the growth of vaccinia virus. The cell line used here was not genetically pure, nor was the virus. By the use of genetically pure clones of HeLa cells and vaccinia virus further analyses of biological and biochemical course of events will be facilitated.

\section{SUMmary}

The growth of dermo-vaccinia virus in HeLa cells and the production of soluble antigens were investigated in detail.

The initial rise in titer of infective particles within the cells was noticed about 10 hours following infection, after which a gradual and continual increase was observed. In coincidence with the initial rise of the cell virus, hemagglutinin became measurable in the cell homogenate. A significant rise in titer of infective particles and hemagglutinin in the medium was retarded by several hours, after which they ran parallel with the increase in titer in the cells. The medium hemagglutinin, however, transcended the cell hemagglutinin in later stage, while the medium virus remained at a lower level than the cell virus.

Complement fixing antigen became measurable in the cells at nearly the same time or a little earlier than hemagglutinin. Origin of a small amount of complement fixing antigen which was measurable in earlier stage was discussed.

Twenty five centigrade was considered as the critical temperature, under which HeLa cells could support the growth of vaccinia virus.

The authors wish to express their gratitude to Dr. M. Kitaoka for his constant interest in this work.

\section{REFERENCES}

CASSEL, W. (1957): Multiplication of vaccinia in the Ehrlich ascites carcinoma. Virology, 3, $514-526$.

Craigie, J. \& Wishart, F. O. (1936a): The complement fixation reaction in variola. Canad. J. Pub. Health, 27, 371-379.

CRAIGIE, J. \& WshaRT, F. O. (1936b): Studies on the soluble substance of vaccinia. I. The dissociation in vitro of soluble precipitable substances from elementary bodies of vaccinia. J. Exper. Med., 64, 803-818.

FelleR, A. E., ENDERS, J. E. \& Weller, M. P. (1940): The prolonged coexistence of vaccinia virus in high titer and living cells in roller tube cultures of chick embryonic tissues. J. Exper. Med., 72, 367-388.

FENNER, F. (1958): The biological characters of several strains of vaccinia, cowpox and rabbit pox viruses. Virology, 5, 502-529.

Maitland, H. B. \& TOBIN, B. M. (1956): The growth of vaccinia virus in the chorioallantois of the developing chick embryo and the production of complement fixing antigen and haemagglutinin. J. Hyg., 54, 102-112.

METCALF, D. (1955): The production of vaccinia hemagglutinin by the chorioallantoic membrane of embryonated eggs. Australian. J. Exper. Biol. \& M. Sc., 33, 45-52. 
NAGLER, F. P. O. (1942): Application of Hirst's, phenomenon to titration of vaccinia virus and vaccinia immune serum. M. J. Australia, 1, 281-283.

OYA, A (1955): On the mode of production of hemagglutinin and virus particles in the chorioallantoic membranes infected with variola and vaccinia viruses. Jap. J. M. Sc. \& Biol., 8, 399-411.

OYA, A. (1956): Growth of vaccinia and variola viruses in the one-day-old fertile hen's egg. Jap. J. M. Sc. \& Biol., 9, 293-302.

SAnFord, K. K., EARle, W. R., Evans, V. J., Walts, H. K. \& Shannon, J. E., (1951): The measurement of proliferation in tissue cultures by enumeration of cell nuclei. Nat. Cnacer Inst., 11, 773-795.

SCHERER, W. F. (1952): Agglutination of a pure strain of mammalian cells (L strain, Earle) by suspension of vaccinia virus. Proc. Soc. Exper. Biol. \& Med., 80, 598-602.

SCHERER, W. F. \& SYVERTON, J. T. (1954): The viral range in vitro of a malignant human epitherial cell (strain HeLa, Gey). I. Multiplication of herpes simplex, pseudorabies, and vaccinia viruses. Am. J. Path., 30, 1057-1067.

SMADEL, J. E., Rivers, T. M. \& HoAgland, C. L. (1942) : Nucleoprotein antigen of vaccinia virus. I. A new antigen obtained from elementary bodies of vaccinia. Arch. Path., 34, 275-485.

TAGAYA, I. (1954): Studies on vaccinia hemagglutinin. 1. On the growth of vaccinia hemagglutinin in the developing chick embryo. Jap. J. M. Sc. \& Biol., 7, 39-48.

TAKANO, K., YAMADA, M. \& YAGINUMA, K. (1956): Growth estimation of HeLa strain cells in tissue culture by nucleus enumeration method. Jap. J. M. Sc. \& Biol., 9, 17-26. 